\title{
Gut-brain interactions in inflammatory bowel disease: A clinician's perspective
}

\author{
THEODORE M BAYLESS MD
}

\begin{abstract}
TM BAYLESS. Gut-brain interactions in inflammatory bowel disease: A clinician's perspective. Can J Gastroenterol 1995;9(5):273-276. While most physicians and some patients consider psychosocial factors important in aggravating already existing inflammatory bowel disease (IBD), most of the information is based on a few recent scientific studies, varied anecdotal observations and a tendency for patients and some physicians to view psychosocial and stress-related issues with speculation, bias and some stigmatization. Patients with proctitis who have experienced recrudescence of mucosal friability and rectal bleeding within a day of a severe life stress provide a dramatic example of such anecdotes. Time-lag studies have indicated that stress, especially major life events, precedes illness aggravation in patients with IBD but that stress is not disease-specific. The symptoms studied, pain and diarrhea, were more likely to be physiological responses to acute stress rather than reflections of increased disease activity. Current scientific research supposes the prospect that environmental factors influence disease susceptibility through the central nervous system. Stress is associated with alterations in both humoral and cellular immune mechanisms in humans and in experimental animals. While psychosocial factors may not initiate inflammation in IBD, it is possible that they lead to alterations in the immune response and thereby alter disease activity. Mind-gut interactions affect salivation, gastric secretion, gastric motility and colonic motility, as well as numerous other gastrointestinal functions. These 'physiological' responses are expected in the IBD patient and perhaps will be accentuated by inflammation and its multiple effects on gut function. Because 10 to $13 \%$ of the general population have a tendency to suffer from irritable bowel syndrome (IBS), it is expected that the same percentage of IBD patients will have both IBD and IBS. An example of clinically relevant alterations in pathophysiology is the association of acute proctosigmoiditis with an increase in IBS symptoms in the left colon. Pain and diarrhea based on distension of an irritable left colon after ileocolonic resection result from excessive distension of the left colon by the larger stool volume following loss of absorptive surface of the ileum and right colon. Patients with IBS are also more symptomatic with small amounts of unabsorbed carbohydrates, such as fructose, sorbitol and lactose. Patients with severe IBS have an irritable small bowel, especially when it is formed into a closed reservoir, such as an ileoanal pouch; these patients have at least eight to 10 bowel movements per day
\end{abstract}

continued on next page

Meyerhoff DD-IBD Center, Johns Hopkins Hospital, Baltimore, Maryland, USA

Correspondence: Dr Theodore M Bayless, Meyerhoff DD-IBD Center, Johns Hopkins Hospital, 600 North Wolfe Street, Baltimore, MD 21205, USA. Telephone 410-955-4916, Fax 410-614-1280

This paper was presented at the Trends in Inflammatory Bowel Disease Therapy meeting, April 6 to 9, 1994, held in Victoria, British Columbia. This paper has also been published in Sutherland LR, et al, eds. Inflammatory Bowel Disease: Basic Research, Clinical Implications and Trends in Therapy. Boston, Dordrecht and London: Kluwer Academic Publishers, 1994
$\mathrm{W}$ HILE MOST PHYSICIANS AND some patients consider psychosocial factors important in aggravating already existing inflammatory bowel disease (IBD), most of the information is based on varied anecdotal observations and is bolstered by a few recent scientific studies. However, belief in an association between the mind and IBD is tempered by a tendency for patients and some physicians to view psychosocial and stress-related issues with speculation, bias and some stigmatization. Patients with proctitis who have experienced recrudescence of mucosal friability and rectal bleeding within a day of a severe life stress provide a dramatic example of such 'hard to dismiss' anecdotes. While psychosocial factors may not initiate inflammation in IBD, it is possible that they lead to alterations in the immune response and thereby alter disease activity. Thus, impulses started in the brain may act as aggravating factors for already established bowel inflammation rather than as primary causative factors.

Physicians have varying opinions about the research linking psychological stress with IBD. Mitchell and Drossman (1) surveyed 1000 members of the American Gastroenterological Association (including 530 in clinical practice and 330 in academic practice plus 110 trainees). They found that, in general, physicians agreed that psychosocial factors contribute to clinical exacerbation of symptoms, especially in ulcerative colitis. However, these clinicians did not believe that such fac- 
because of the spasticity and small capacity of the ileoanal pouch. The stomach to pouch transit time may also be quite rapid. Explaining the coexistence of IBD and IBS to the patient is often quite helpful to the patient and to the doctor. One hopes that the scientific explanations of these mind-gut interactions are forthcoming.

Key Words: Brain-gut interaction, Inflammatory bowel disease, Irritable bowel syndrome, Psychological factors, Stress

\section{Interactions tractus digestif-cerveau dans la maladie inflammatoire de l'intestin : point de vue d'un clinicien}

RÉSUMÉ : Si la plupart des médecins et certains patients considèrent les facteurs psychosociaux importants dans l'aggravation d'une maladie inflammatoire de l'intestin pré-existante (MII), la plupart de ces renseignements se basent sur quelques rares études scientifiques récentes, sur quelques observations anecdotiques et sur une tendance chez certains patients et médecins à percevoir les questions psychosociales ou liées au stress avec spéculation, partialité et une certaine forme de stigmatisation. Les patients atteints de proctite qui ont manifesté une recrudescence de la friabilité muqueuse et des hémorragies rectales au lendemain d'un stress intense sont un exemple frappant de telles anecdotes. Les études réparties dans le temps ont indiqué que le stress, particulièrement les événements marquants de la vie, précède l'aggravation de la maladie chez des patients atteints de MII, mais que le stress n'est pas spécifique à la maladie. Des symptômes étudiés, la douleur et la maladie étaient davantage liées à des réponses physiologiques à un stress aigu plutôt que le reflet d'une activité accrue de la maladie. La recherche scientifique actuelle suppose que les facteurs environnementaux influent sur la sensibilité à la maladie par le biais du système nerveux central. Le stress est associé à des altérations des mécanismes immunitaires humoraux et cellulaires chez l'homme et chez les animaux de laboratoire. Bien que les facteurs psychosociaux puissent ne pas déclencher l'inflammation dans la MII, il est possible qu'ils entraînent des altérations de la réponse immunitaire et influent, de ce fait, sur l'activité de la maladie. Les interactions entre l'esprit et le tractus digestif affectent la salivation, les sécrétions gastriques, la motilité gastrique et la motilité du côlon, de même que de nombreuses autres fonctions gastro-intestinales. Ces réponses physiologiques sont prévisibles chez le patient atteint de MII et seront peut-être accentuées par l'inflammation et ses multiples effets sur la fonction intestinale. Parce que de 10 à $13 \%$ de la population générale a tendance à souffrir du syndrome du côlon irritable (SCI), il est prévisible que le même pourcentage de patients atteints de MII souffrent concurremment de SCI. Un exemple d'altération cliniquement pertinente de la physiopathologie est l'association de proctosigmoïdite aiguë avec exacerbation des symptômes de SCI dans le côlon descendant. La douleur et la diarrhée basées sur la distension d'un côlon descendant irritable après une résection iléocolonique résultent d'une distension excessive du côlon descendant causée par un plus fort volume de selles consécutif à la perte de surface disponible pour l'absorption au niveau de l'iléon et du côlon ascendant. Les patients qui souffrent de SCI sont plus symptomatiques en présence de petites quantités de glucides non absorbées, comme le fructose, le sorbitol et le lactose. Les patients qui souffrent de SCI grave ont un intestin grêle irritable, particulièrement lorsqu'il a la forme d'un réservoir fermé, comme c'est le cas pour le réservoir iléoanal. Ces patients vont à la selle de huit à dix fois par jour à cause de la spasticité et de la faible capacité du réservoir iléoanal. Le transit entre l'estomac et le réservoir peut également être assez rapide. Il est souvent utile pour le patient et le médecin d'expliquer au patient la coexistence d'une MII et du SCI. Il est à espérer que les explications scientifiques de ces interactions entre le tractus digestif et le cerveau pourront se confirmer.

tors were involved in the etiology of IBD. Older physicians, based on their clinical experience, were more convinced of the role of psychosocial fac- lieve there was any personality style characteristic of IBD patients, nor did they feel that the psychosocial impact on patients with IBD was any different from that observed with other chronic illnesses such as arthritis or diabetes mellitus.

\section{KNOWN MIND-GUT PHYSIOLOGICAL INTERACTIONS}

Specific physiological 'reflexes' or gut responses to a meal are well documented. These easily stimulated mindgastrointestinal tract reactions include salivation, gastric secretion, gastric motility and colonic motility. Some are mediated via the enteric nervous system (or small brain) (2).

It is now acceptable to state that intestinal inflammation has many neurohormonally influenced effects on the gastrointestinal tract, such as the secretory diarrhea of IBD and the intestinal cramping experienced by many patients with colitis. The 'physiological' responses that occur in a healthy individual would still be expected to occur in the IBD patient and perhaps to be accentuated by inflammation and its multiple effects on gut function.

\section{EFFECTS OF STRESS ON THE GASTROINTESTINAL TRACT}

Many of the physiological events that occur in healthy persons and that may be aggravated by intestinal inflammation can also be effected by various psychic stimuli such as fear, anger or stress. The salivation and increased gastric secretion and gastric motility that occur when one thinks of a delicious meal is well documented by physiologists. Changes in intestinal and colonic motility in response to various stressful stimuli were well demonstrated by Drossman (3). Few would deny that emotional distress will produce changes in bowel function in many individuals and will produce $a b-$ dominal discomfort in some (4).

Some of the symptoms described by patients with IBD probably relate to changes in motility and in awareness of painful sensations. These motility changes and pain may, at times, be independent of disease activity. 


\section{MECHANISMS FOR STRESS-GUT FUNCTION RELATIONSHIP}

Stress and gut physiology are presumably related through the highly innervated nerve plexi and neuroendocrine links to the enteric nervous system ('the small brain') and its spinal and autonomic connections to the central nervous system $(2,5)$. Thus, psychological or environmental stimuli are able, by their neural-hormonal connections, to have an effect on motility and on visceral perception. The mind-gut system is further modulated by various neurotransmitters, including vasoactive intestinal peptide (VIP), thyroid-releasing hormone, 5hydroxytryptamine, cholecystokinin, substance $\mathrm{P}$ and the enkephalins.

\section{ANIMAL RESEARCH ON STRESS AND MUCOSAL CHANGES}

A number of studies in animals support the presence of an association between stress and changes in mucosal morphology and, indirectly, with gastrointestinal disease. Acute gastric erosions were produced in rats by physical restraint, prolonged swimming or premature weaning (3). Monkeys placed in a conditioned anxiety situation or restrained in chairs developed gastroduodenitis, and two had chronic colitis (6). Interestingly, colitis led to the death of four gibbons after the death of their mate. This was considered a major disruption in the social environment by the authors $(7,8)$. The studies of the cotton-topped tamarin by Drossman (9) show that they remain well in the wild but when caged with a disruption of their social order, most cottontopped tamarins develop ulcerating colitis.

\section{HUMAN RESEARCH ON PSYCHOSOCIAL FACTORS AND SYMPTOMS}

Clinical and epidemiological studies have suggested a relationship between psychosocial stress and symptom onset or exacerbation (3). Social structure is characterized as a 'permissive' factor in susceptibility to disease. Persons who experience social disorganization are more susceptible to various medical conditions. The first cases of ulcerative colitis described in Bedouin Arabs occurred in individuals who were moved from their traditional nomadic life to 'modern' living in government housing.

\section{EFFECTS OF STRESS ON PATIENTS WITH IBD}

Time-lag studies have indicated that stress, especially major life events, precedes illness aggravation in patients with IBD but that this is not diseasespecific. The symptoms studied, pain and diarrhea, were more likely to be physiological responses to acute stress rather than reflections of increased disease activity.

North and colleagues (10) studied the effects of major life events and mood on bowel symptoms and pain in 32 patients with IBD, but found no association with symptoms one or two months later. However, they did note an association between depressive symptoms and the severity of symptoms.

Duffy and associates (11) found that patients with a history of major life events at the outset of the study had a significantly greater risk of active disease than those without such a history. They showed a relationship between stress and gastrointestinal symptoms when they focused on acute responses to stress rather than on events that had occurred months earlier. By focusing on daily stressors, other investigators (12) found a significant association between acute daily stress and bowel symptoms over a four-week period in 10 patients with Crohn's disease.

To summarize the few careful studies of a relationship between psychosocial factors and symptoms in patients with IBD, first, epidemiological and clinical observations have, in the past, suggested an association between stress and illness exacerbation, which is general and not unique to IBD; second, recent studies relating major life events with symptom exacerbation in patients with IBD have yielded somewhat conflicting results but a positive association is suggested; third, the major stressors are not unique to IBD and in- clude illness or death in the family, separation or divorce, other major loss or interpersonal conflict; lastly, daily stressors seem to be associated with exacerbation of symptoms in patients with IBD, as well as with other illnesses.

\section{CONCURRENT PSYCHOLOGICAL ASSOCIATIONS WITH IBD}

Studies of unselected populations indicated that the psychological profiles of patients with IBD are similar to normal subjects, although with wide variation. Patients with IBD have slightly higher frequencies of psychiatric diagnoses and slightly greater psychological distress (most often related to anxiety and depression) than normal controls, but at a level comparable with patients with other chronic illnesses. Patients with IBD clearly have fewer psychological problems than patients coming to physicians with the irritable bowel syndrome (IBS). Patients with Crohn's disease have more psychological disturbances than patients with ulcerative colitis, and the degree of psychological distress correlates directly with the severity and chronicity of disease (which is usually greater with Crohn's disease). These findings suggest that psychological disturbances are a component of illness in general rather than being etiological or specific for IBD.

\section{MODULATION OF IMMUNE REGULATION BY STRESS}

Current scientific research supports the prospect that environmental factors influence disease susceptibility through the central nervous system. Stress is associated with alterations in both humoral and cellular immune mechanisms in humans and in experimental animals. While psychosocial factors may not initiate inflammation in IBD, it is possible that they lead to alterations in the immune response and thereby alter disease activity.

The effects of psychosocial stressors on the immune system are probably mediated through bidirectional, interconnected pathways among the brain, enteric nervous system, neuroendocrine axis and immune system. 
There is increasing evidence that alterations of enteric nervous system function may be important in the pathogenesis of IBD. Substance $P$ appears to be a mediator of neurogenic inflammation in the gastrointestinal tract, the skin and the respiratory tract. Interleukin-1 has effects on intestinal epithelial ion secretion which contributes to IBD diarrhea. VIP also stimulates intestinal secretion and is a known mediator of diarrhea. VIP-containing neurons and rectal mucosal VIP levels are increased in patients with Crohn's disease.

\section{COEXISTENCE OF IBS AND IBD}

IBS comprises a quite common combination of symptoms that accounts for one-third to one-half of all patients seen in many digestive disease clinics and practices. There is unanimity of opinion regarding the sensitivity of IBS patients to acute and chronic stress.

Because 10 to $13 \%$ of the general population have a tendency to suffer from irritable bowel syndrome (IBS), it is expected that the same percentage of IBD patients will have both IBD and IBS. Because IBS is much more common than IBD, it is not surprising that many patients with IBD were initially told that they had IBS. Conversely, when a patient who truly had IBS later develops IBD the physician usually forgets the preexisting IBS, but the patient assumes she or he had IBD all along. The nega-

\section{REFERENCES}

1. Mitchell CM, Drossman DA. Survey of the AGA membership relating to patients with functional gastrointestinal disorders. Gastroenterology 1987;92:1282-4.

2. Wood JD. Enteric neuroimmune interactions. In: Walker WA, Harmatz PR, Wershil BK, eds. Immunophysiology of the Gut. San Diego: Academic Press, 1993.

3. Drossman DA. Psychosocial considerations in gastroenterology. In: Sleisenger MH, Fordtran JS, Cello JP, Feldman M, eds. Gastrointestinal Disease: Pathophysiology, Diagnosis, Management. Philadelphia: WB Saunders Co, 1993:3-17.

4. Drossman DA, Sandler RS, McKee DC, Lovitz AJ. Bowel patterns among subjects not seeking health care. Use of a questionnaire to identify a population tive influence of this type of assumption on the physician-patient relationship is not measurable but certainly is possible (13).

Whether some of the stress-related symptoms described in some patients with IBD are due, even in part, to coexisting IBS is not known. Definitive methods of identifying the gut motor responses of IBS are needed for a definitive answer to this question.

\section{EXAMPLES OF CLINICALLY RELEVANT PATHOPHYSIOLOGY}

Some examples of clinically relevant alterations in pathophysiology include the association of acute proctosigmoiditis with an increase in IBS symptoms in the spastic and inflamed left colon. Because of spasm in the sigmoid colon, often accentuated by a large or fatty meal, the patient experiences distension of the descending colon and pain in the left upper quadrant. The patient and the physician may incorrectly interpret this 'splenic flexure syndrome' as an extension of the still distally located inflammation.

Pain and diarrhea based on distension of an irritable left colon after ileocolonic resection result from excessive distension of the left colon by the larger stool volume following loss of absorptive surface of the ileum and right colon. Again, the patient (and even the doctor) may think that the Crohn's

with bowel dysfunction.

Gastroenterology 1982;83:529-34.

5. Mayer EA, Raybould HE. Role of visceral afferent mechanisms in functional bowel disorders. Gastroenterology 1990;99:1688-704.

6. Porter RW, Brady JV, Conrad D, Mason JW, Galambos R, Rioch D. Some experimental observations on gastrointestinal lesions in behaviorally conditioned monkeys. Psychosom Med 1958;20:379-94.

7. Stout C, Synder RL. Ulcerative colitis-like lesions in Siamang gibbons. Gastroenterology 1969;57:256-60.

8. Engel GL. Psychological factors in ulcerative colitis in man and gibbon. Gastroenterology 1969;57:362-4.

9. Drossman DA. Is the cotton-topped tamarin a model for behavioral research? Dig Dis Sci 1985;30:24S-7S. disease has suddenly appeared in the descending colon, which was normal by colonoscopy just before surgery. Patients with IBS are also more symptomatic with small amounts of unabsorbed carbohydrates, such as fructose, sorbitol and lactose.

Patients with severe IBS also have an irritable small bowel, especially when it is formed into a closed reservoir, such as an ileoanal pouch; these patients have at least eight to 10 bowel movements per day because of the spasticity and small capacity of the ileoanal pouch. The stomach to pouch transit time may also be quite rapid. Explaining the coexistence of IBD and IBS to the patient is often quite helpful to the patient and to the doctor. Avoiding this operation in a patient with severe IBS and ulcerative colitis is an even greater service to all concerned.

Although the thesis of coexistence of IBS and IBD is a simple one it is rarely mentioned in articles or textbooks. I have found this concept very helpful in evaluating and advising 'complicated' or 'difficult' patients with IBD (13).

Functional gastrointestinal disease probably coexists with other 'organic' illnesses, such as peptic ulcer and reflux esophagitis. The astute physician will be alert to these overlapping diagnoses.

As a final thought, one hopes and assumes that scientific explanations of these mind-gut interactions are forthcoming.

10. North CS, Alpers DH, Helzer JE, Spitznagel EL, Clouse RE. Do life events or depression exacerbate inflammatory bowel disease? Ann Intern Med 1991;114:381-6.

11. Duffy LC, Zielezny MA, Marshall JR, et al. Relevance of major stress events as an indicator of disease activity prevalence in inflammatory bowel disease. Behav Med 1991;17:101-10.

12. Garrett VD, Brantly PJ, Jones GN, McKnight GT. The relation between daily stress and Crohn's disease. J Behav Med 1991;14:87.

13. Bayless TM. Coexistent irritable bowel syndrome and inflammatory bowel disease. In: Bayless TM, ed. Current Management of Inflammatory Bowel Disease. Toronto: Marcel Dekker Inc, 1989:59-62. 


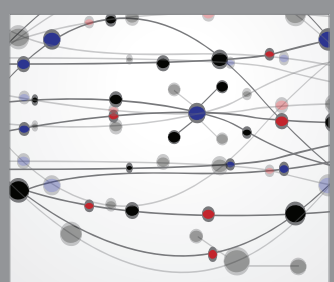

The Scientific World Journal
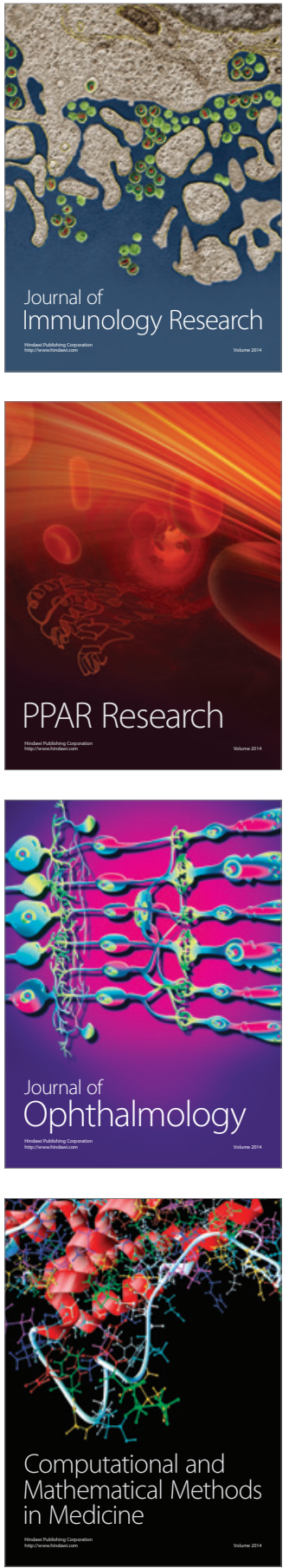

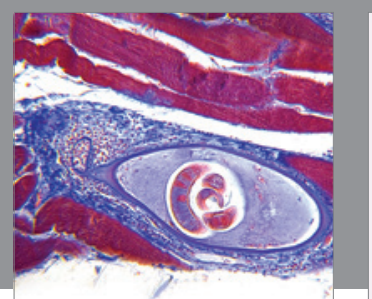

Gastroenterology Research and Practice

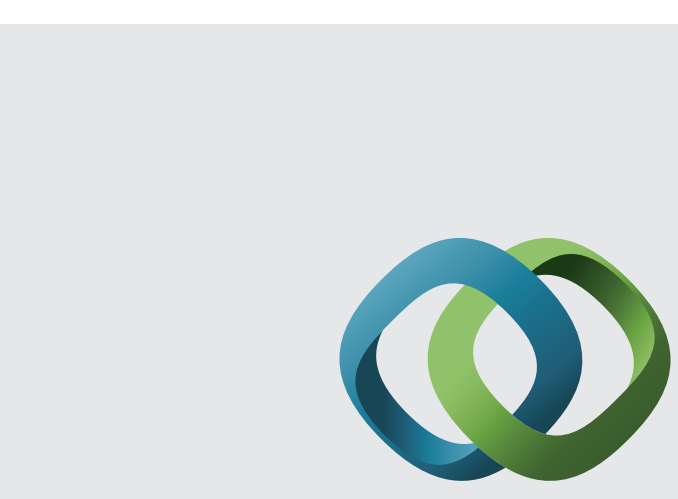

\section{Hindawi}

Submit your manuscripts at

http://www.hindawi.com
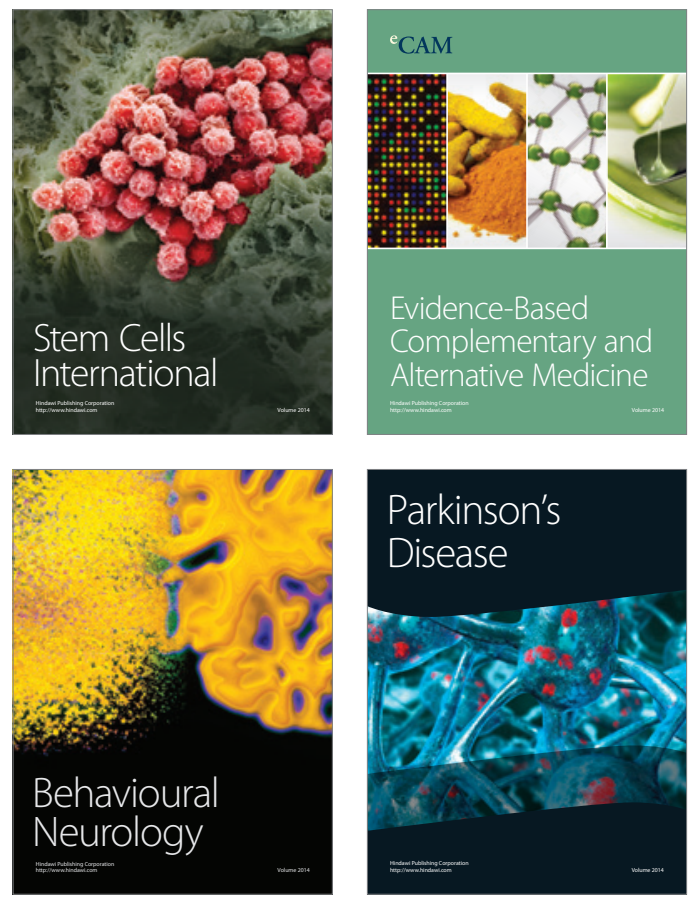
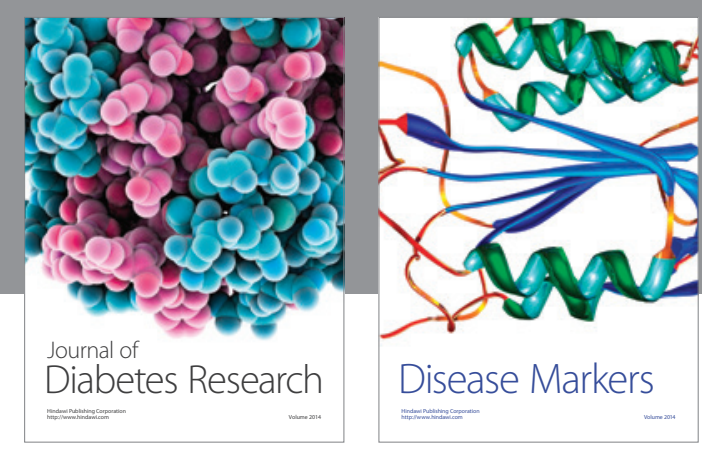

Disease Markers
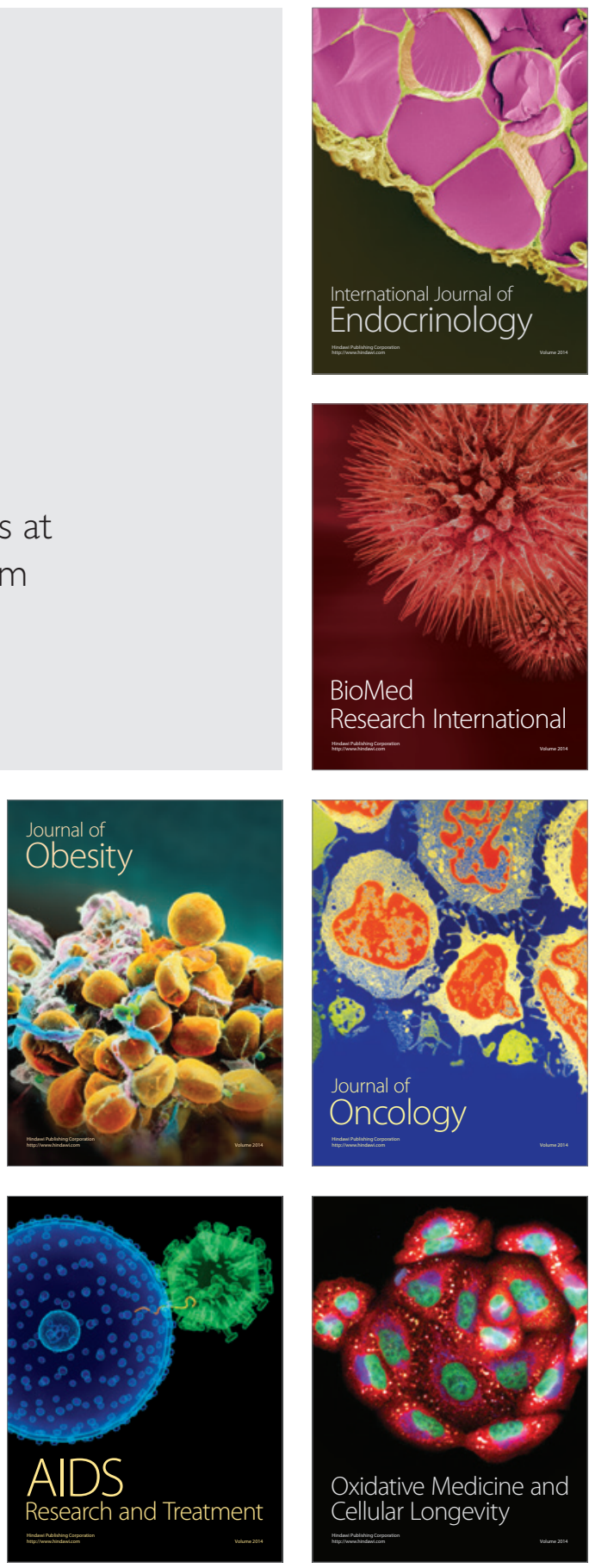